\title{
Challenges and Strategies for Rapid Response in Disaster Relief Operations in Ghana
}

\author{
Article by Japhet Baidoo \\ Disaster Management, Texila American University \\ Email: japhetbaidoo@yahoo.com
}

\begin{abstract}
Natural disasters are catastrophes that are beyond the control of humans. However, the effects of natural disasters can be reduced through rapid response and effective post-disaster management strategies. This study examines the barriers to effective disaster relief operations in Ghana and propose strategies for ensuring efficient response in disaster relief operations. Questionnaires were used to obtain data from officials of ten major disaster relief organizations in Ghana. The study revealed a number of constraints affecting disaster relief operations in Ghana. Key among these are lack effective planning, lack of logistics, people's behavior and perception and lack of coordination and corporation. Strategies for efficient disaster relief operations should include appropriate incountry training and education to personnel, proper coordination among stakeholders and improvement in logistical suppliers through increased funding for disaster relief organizations.
\end{abstract}

Keywords: Natural Disasters and Catastrophes, Rapid Response, Disaster Relief Operations and Relief Organizations.

\section{Introduction}

Natural disasters are catastrophes that are beyond the control of humans. However, the effects of natural disasters can be reduced through rapid response and effective post-disaster management strategies. Disaster relief operations, in general, are carried out by relief agencies in collaboration with security agencies such as the military, focusing on transportation of food, first aid material, equipment, and rescue personnel from supply points to many destination nodes geographically dispersed over the disaster region (Christopher \& Tatham, 2011).The evacuation and transfer of people affected by disasters to designated health care centers rapidly and safely also form an integral function of relief organizations (Barbarosog et al, 2002).

In recent times, the most alarming and devastating disasters in Ghana are floods, fires and epidemic (Addai, et al, 2016; Ntanjal, et al, 2017). These disasters have claimed many lives and cost the nation millions of dollars annually (NADMO, 2014). Seriously, response to disasters and managing of disasters augmented by disaster relief organizations in Ghana present operational constraints to regional and national disaster response and management capacity. For example, on several occasions, the response to floods and fire disasters by the disaster relief organizations such as the National Disaster Management Organization (NADMO), the Ghana National Fire Service (GNFS) among the various organizations have been questioned. This is against the backdrop that on a number of occasions, there were experiences of delays and flaws in disaster response execution leading to increased casualties and worsened conditions of disaster victims (Bempah and Olyhus, 2017). Arguably, coordination of logistics in disaster relief operations especially during emergencies is very daunting due to the distinct nature of the disaster and emergencies as well as the high involvement of stakeholder organizations (Aboagye, Dari \& Koomson, 2013; Allotey, Arku \& Amponsah, 2010). This notwithstanding, it is imperative for disaster relief organizations to remain steadfast in their quest to swiftly respond to disasters, reduce human, physical, and economic losses that often accompany disasters.

\section{Statement of problem}

The key to improved ability, capability and speed in disaster relief efforts is to examine the challenges confronting disaster relief organizations and provide appropriate antidotes in addressing 
them. However, in most cases, the response of disaster relief organizations in Ghana to disasters has been described as poor, at best (Buatsi, 2007). Yet, in the case of Ghana, no adequate explanation has been provided to explain the failure of disaster organizations to promptly respond to emergency situations. Similarly, no detailed examination has been conducted to ascertain why the operational flaws associated with disaster relief operations in Ghana continue to occur. There is therefore the need examine the challenges to rapid response in disaster relief operations in Ghana. It is against this backdrop that this study attempts to provide an in-depth exposition of the challenges to rapid response in disaster relief operations in Ghana.

\section{Objectives of the study}

The main aim of the study is to assess the challenges associated with rapid response in disaster relief operations in Ghana. Specifically, the study seeks:

I. To examine the constraints to effective response in disaster relief operations.

II. To propose strategies of ensuring efficient response in disaster relief operations.

\section{Research questions}

The study is underpinned by the following research questions:

I. What are the constraints to effective response in disaster relief operations?

II. How can efficient response in disaster relief operations be achieved?

\section{Theoretical framework}

The study focuses on disaster relief operations in Ghana. Humanitarian logistics and disaster management literature distinguishes between different stages of disaster relief. In the opinion of Long and Wood (1995) and Van Wassenhove (2006), the least distinction is between preparation and postevent phases. Whereas on a more detailed level, Ludema (2000) differentiates between rehabilitation, emergency relief and development; Pettit and Beresford (2006) between response, preparedness and recovery; Safran (2003) between prevention, transition and recovery; Kova'c and Spens (2007) between preparation, immediate response and reconstruction; and Altay and Green (2006) between mitigation, preparedness, recovery and response.

Altay and Green (2006) attempt to capture the distinction made by the complete phases in consecutive order and in consistent with the full Disaster Management Cycle shown in figure 1.The cycle shows the ongoing course by which businesses, civil society and governments, plan for and diminishing the impact of disasters, react during and immediately following a disaster, and steps to take to recover after a disaster occurrence. Appropriate actions at all points in the cycle lead to better warnings, greater preparedness, and prevention of disasters or reduction of vulnerability during the next iteration of the cycle. The complete disaster management cycle includes public policies and plans shaping, that either mitigate their effects on people or modify the causes of disasters, infrastructure and property.

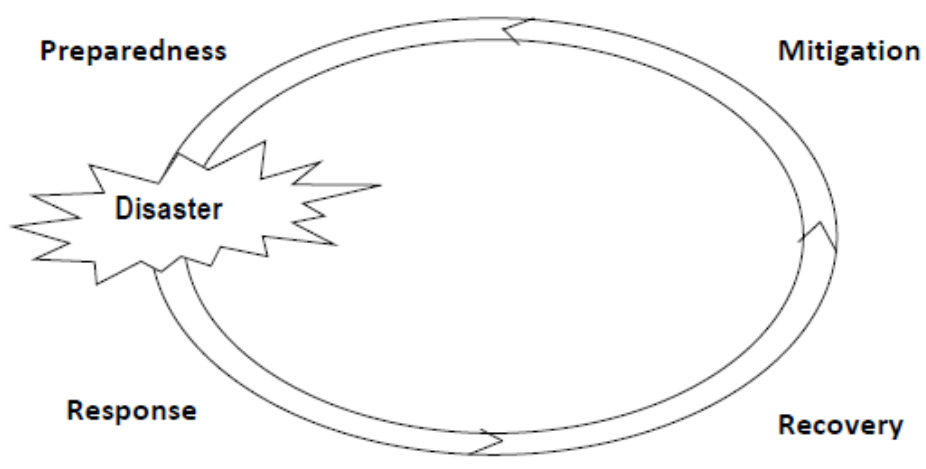

Figure 1. Disaster management cycle

Source: Tuscaloosa county disaster management cycle (2003). 


\section{Mitigation}

Mitigation activities actually eradicate or diminish the chance of disaster occurrence, or lessen the effects of inevitable disasters. According to Tomasini and Van Wassenhove, (2009b), Mitigation measures include laws and mechanisms that diminish the susceptibility of the population and intensifies their resilience. For example, updates of vulnerability analyses; public education; preventive health care; land use management and zoning; safety codes and regulations for building usage; and building codes.

Mitigation depends on the integration of appropriate measures in regional and national development planning. Mitigation efficiency will also depend on the readiness of information on emergency risks, hazards and the countermeasures to be taken. The whole disaster management cycle and mitigation phase, indeed, comprises the shaping of public plans and policies that either mitigate disasters effects on property, people, and infrastructure or modify their causes.

\section{Preparedness}

A well-prepared response is much more effective than ever. Tomasini and Van Wassenhove, (2009b) demonstrated that, preparedness addresses the strategy already in place that allows implementation of a successful operational response in the theatre. The objective of emergency preparedness programs is to achieve an acceptable level of readiness to react to any emergency situation. That is, through programs that strengthen the managerial and technical capacity of governments, communities and organizations. These measures, also described as logistical readiness to deal with disasters can be enhanced by having response procedures and mechanisms, developing long-term and short-term strategies, public education, rehearsals and building timely warning systems (Nisha de Silva, 2001). Based on the tasks and skills required to respond, Tomasini and Van Wassenhove (2009a) argued that, supply chain management should be at the center of the preparedness strategy of any organization, so as to enhance the flow of people, knowledge, information, finance and materials.

\section{Response}

Emergency response is meant to provide immediate assistance to improve health maintain life, and support the confidence of the affected population. Such aid may range from provision of precise, but limited, such as assisting refugees with, temporary shelter, transport and food, in establishment of semi-permanent settlements in camps and other locations. Emergency response may also involve initial repairs to damaged buildings and infrastructure. Meeting the basis needs of the people until more permanent and sustainable solutions arrive is the primary focus in the response phase.

Long and Wood (1995) have shown that there is an abundance of aid agencies focusing on relief after natural disasters. Therefore, it is often in chaos among aid agencies, about which resources are available and which are not, or which are demanded in priority. In some situations, even the contribution and involvement of suppliers are unpredictable (Tomasini and Van Wassenhove, 2009a). This scenario creates duplicated efforts and materials, and many redundancies (Simpson, 2010).

\section{Recovery}

This phase of the Disaster Management Cycle focuses on providing long term assistance to victims. Here, actors and institutions begin to assist victims in the location of their family and friends (Lamont, 2005) after the immediate response. There is no exact point at which immediate relief can transform into recovery and then into long-term maintainable development. There will be many opportunities during the recovery period to enhance, prevent and increase preparedness, thus reducing vulnerability. Ideally, there should be a smooth changeover from recovery to on-going development.

Recovery activities continue until all systems become better or return to normal. In both short and long term, Recovery measures include temporary housing; returning vital life-support systems to minimum operating standards; health and safety education; counseling programs; reconstruction; public information and economic impact studies. Information services and resources include data collection relating to documentation of lessons learned and rebuilding. All these can be attained through efficient and effective coordination. 
DOI: $10.21522 /$ TIJMG.2015.04.02.Art007

ISSN: $2520-310 \mathrm{X}$

\section{Research methodology}

The perspective of the research was based on Ghana and it involved the major disaster relief organizations in Ghana. The study employed descriptive research design that focused on in-depth examination of the associated challenges in disaster response and strategies for overcoming these. Twelve major organizations were targeted for the study, out of which ten agreed to participate. These were

(1) United Nations Humanitarian Response Depot (UNHRD);

(2) World Vision - Ghana,

(3) Adventist Development Relief Agency (ADRA);

(4) CARE International;

(5) National Disaster Management Organization (NADMO):

(6) Ghana Police Service;

(7) Ghana National Fire Service;

(8) National Ambulance Service (NAS);

(9) St. John's Ambulance Service (SAS) and;

(10) United Nations High Commission for Refugees.

The two that couldn't respond to my questions before compiling and analysis are

1. Ghana Health Service

2. Ghana Red Cross Society

A senior official (being the mouthpiece) representing each respective organization was involved in the study.

\section{Data collection and analysis}

In line with the qualitative and quantitative research approach, questionnaires and observations were used to elicit responses from the study participants. According to Yin (2004), questionnaires are the most appropriate method for case study. The use of questionnaires ensured that standardized data were collected from identical organizations in this case disaster relief organizations, without the need to have face to face interaction. Apart from these, it saves time and resources. Also, the questionnaire enabled the researcher to collect relevant data in respect of the same variables for everyone in the sample selected (Yin, 2004). The questionnaires consisted of Likert Scale statements that sought the opinion of respondents on the constraints confronting their organizations when it comes to disaster management. The data collected were analyzed using the SPSS Software. Pictures taken during field observations were used to support findings from the questionnaire data.

Based on the responses to the questionnaire using the above scale, the Weighted Mean Average formula was used to compute the overall results for the various variables to address the research questions.

$\mathrm{WMA}=\frac{\sum \mathrm{W}}{\mathrm{AN}}=\frac{5 \mathrm{n}_{5}+4 \mathrm{n}_{4}+3 \mathrm{n}_{3}+2 \mathrm{n}_{2}+1 \mathrm{n}_{1}}{5 \mathrm{~N}} \ldots \ldots \ldots \ldots \ldots$ eq. 1

The formula above is explained below:

WMA = Weighted Mean Average

$\mathrm{A}=$ Highest weight (in this case 5)

$\mathrm{N}=$ Sample Size

$\mathrm{n} 1=$ Number of responses to "Strongly Disagree"

$\mathrm{n} 2=$ Number of responses to "Disagree"

$\mathrm{n} 3=$ Number of responses to "Indifferent"

$\mathrm{n} 4=$ Number of responses to "Agree"

n5 = Number of responses to "Strongly Agree"

The results from the computations using the above formula was then compared with the Vagias (2006) Means Range values to obtain the appropriate interpretation to the specific variable in the questionnaire. 


\section{Results and discussion}

The study sought the views of the respondents on the challenges that are peculiar to their organizations. This was done with reference to the Disaster Management Cycle, which formed the theoretical framework of the study. Thus, respondents were asked to identify challenges they encounter and indicate which phase or phases of the disaster management cycle they experience the challenges identified. The results are illustrated in Figure 2.

\section{Mitigation phase}

From Figure 2, peoples' behavior and perception towards disasters (90\%) constituted a major constraint to disaster relief during the mitigation phase. This is confirmed by the findings in plate 1 that depicts how people behave towards disaster scenes - everyone in desperation wanting to be the first to catch the glimpse of disaster when it strikes. From the results, it is obvious how people were eager to catch a glimpse of disaster and by so doing obstructing free flow and easy access of disaster relief personnel and equipment to disaster sites. This outcome confirms the finding of Okoampa (2007) that there is the perception among Ghanaians that Ghana is "safe" and that disasters are unlikely to occur and this affects the Ghanaian's level of preparedness as well as mitigation efforts.

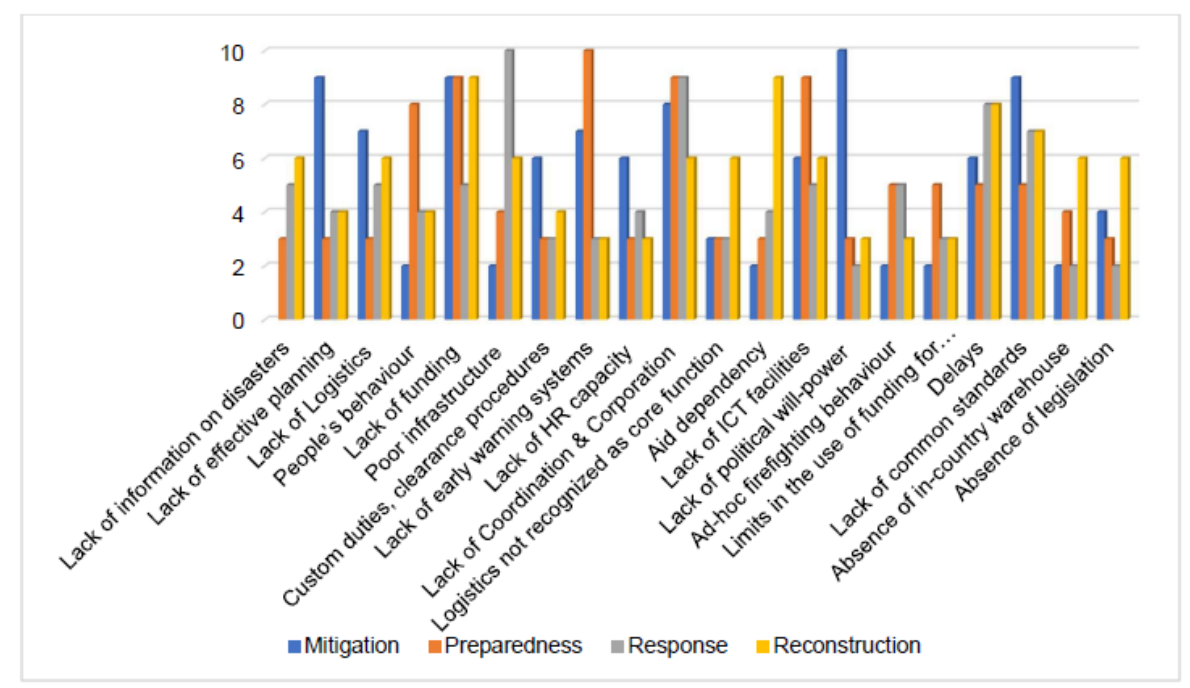

Figure 2. Challenges militate against disaster relief operations in ghana

Source: Field Data, 2016

Another constraint during the mitigation phase was lack of political will-power to execute disaster mitigation projects. This was followed by lack of effective planning, lack of common standards, lack of funding and inappropriate donations, lack of effective coordination and corporation with other disaster relief originations. 


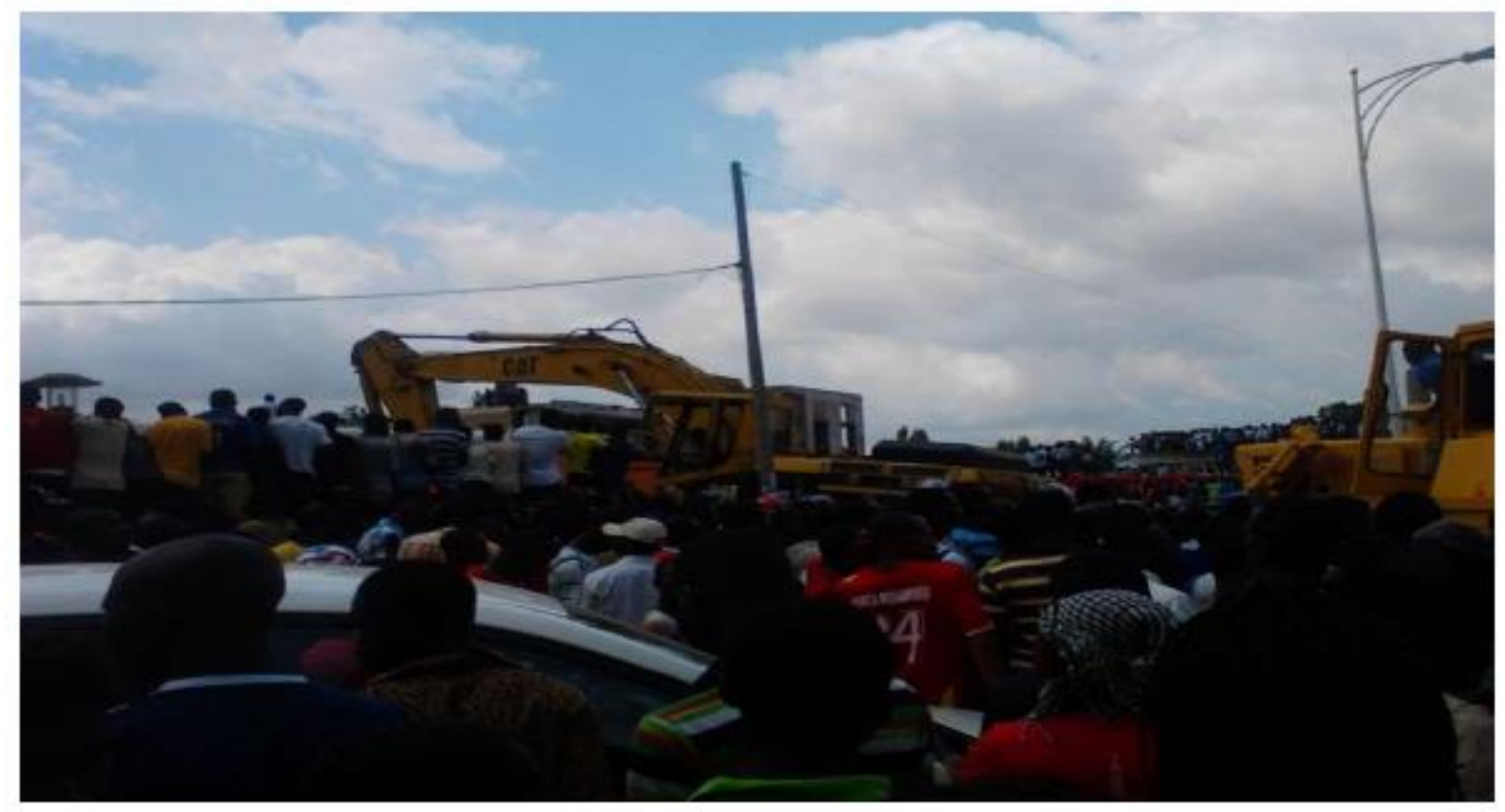

Plate 1. Large crowd "competing" with excavators for space at a disaster site

Source: Adomfmonline.com, 2015

\section{Preparedness phase}

At the preparedness phase, the results showed that the major challenges faced were lack of early warning systems, coordination and collaboration among disaster relief organizations and lack of ICT facilities, lack of funding and inappropriate donations, people's behaviour and perception about disasters and lack of logistics. The rest which were noted to be minor challenges were lack of information on disasters and effective planning, ad-hoc fire-fighting behaviour and poor infrastructure.

With respect to lack of information and early warning systems, it is important to note that knowing the causes for disasters help in setting early warning indicators to mitigate the disasters or prepare for them. In this regard, the use of ICT facilities could help provide relevant information necessary for planning to mitigate any disaster that might strike as also confirmed in the findings of Kovacs and Spens (2007). The implication of these challenges at mitigation phase is that they have rippling effects on the preparedness phase.

\section{Response phase}

When it comes to response to disasters, the results in figure 2 showed that $60 \%$ of the respondents were of the view that their respective organizations often experience delays in responding to disaster relief operations, while $40 \%$ of the respondents stated otherwise. When pressed to provide reason for the delays, poor infrastructure, lack of coordination and corporation and lack of information as well as lack of ICT facilities were identified as the main constraints inhibiting timely response to disasters. The picture below illustrates how the nature of road infrastructure in some parts of the country constrain the activities of disaster relief organizations. 


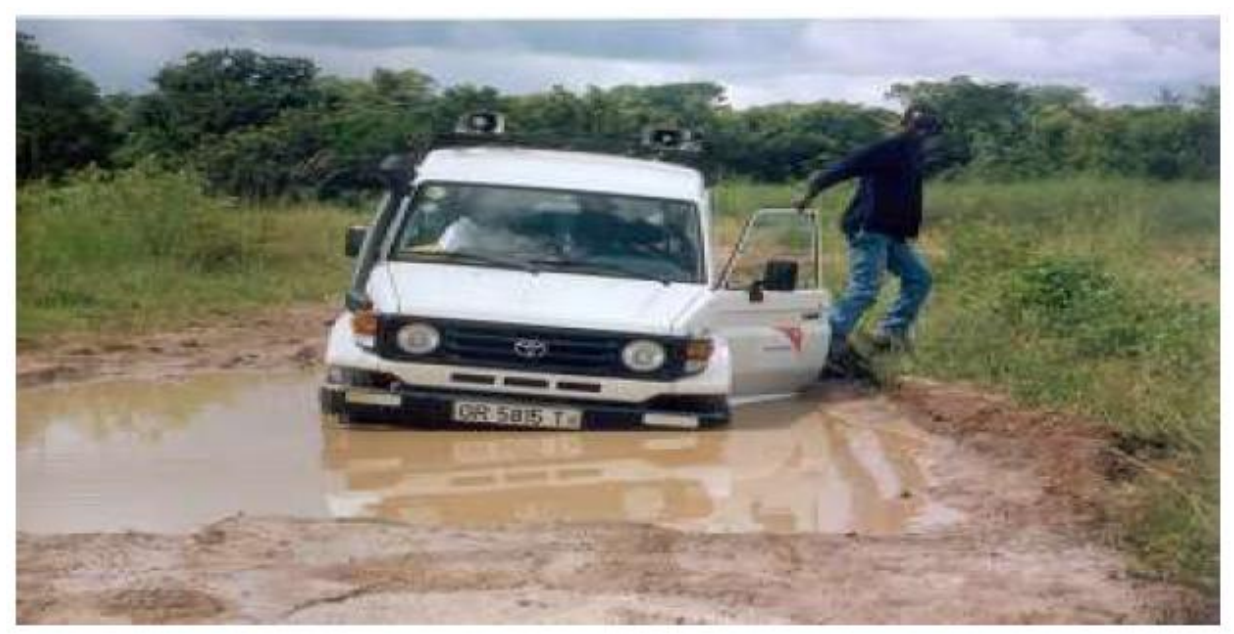

Plate 2. World vision disaster relief team

Source: World vision ghana, 2016

Though Ghana is seen as a country with well-developed transport infrastructure in West Africa (Pederson, 2003), the state of the road network with an abundance of unpaved roads leads to frequent vehicle breakdowns. Another important challenge at the response phase was lack of HR capacity which was also evident in the study conducted by Addai, et al, (2016).

\section{Reconstruction phase}

The major challenges that disaster relief organizations in Ghana face during reconstruction phase were aid dependency and lack of funding. The rest though on the minor side include delays, lack of common standards of operations, absence of legislation and in-country warehousing, lack of ICT facilities and lack of coordination and collaboration among disaster relief organizations. These findings are in line with the assertion that, countries that rely on aid for emergency relief will have a challenge ensuring effective and efficient disaster management.

\section{Conclusion}

The results from the study shows that despite the efforts by disaster relief organizations in responding to various disasters in Ghana, they are confronted with important constraints. Key among these are lack of lack of effective planning, absence of early warning systems and limited collaboration among relief organizations. These challenges which resonates through all the phases of the Disaster Management Cycle act as barriers to effective and efficient disaster risk reduction and mitigation in the country. The challenges militating against disaster relief operations in Ghana do not only depend on the type of disasters, organizations but also on the activities related to different phases of disaster relief. Therefore, short, medium to long term measures are needed in addressing the challenges so as to achieve effectiveness and efficiency in disaster management and humanitarian logistics operations in Ghana.

\section{Recommendations}

In order to overcome the constrains identified in the study and ensure that organizations respond effectively to disasters, measures should be put in place to address the challenges facing these organizations. Hence, the following recommendations are made:

I. Stakeholders in disaster relief operations in Ghana must come together and draw up collaborative and comprehensive plans, modalities and strategies to ensure improved speed and co-ordination in disaster relief efforts. This will help to establish a common platform for sharing knowledge and information, a practice that will help to improve response time to disasters, reduce cost to improve efficiency.

II. Appropriate simulation exercises should be organized often among the relief organizations. This will improve on the relief response effort effectively and efficiently. Knowledge acquisition is 
also important among the staff. One such training is the Msc Disaster Management programme run by the University of Cape Coast in Ghana. Disaster relief organizations should partner the University to provide professional training to personnel to improve their skills and expertise.

III. Disaster relief organizations in Ghana should be adequately resourced with the logistics such as relief items, vehicles, warehouses and funding to enable them respond to disasters in good time. In particular, there is the need to set early warning systems by investing in modern ICT systems. This will help modernize relief operations and make organizations more responsive to disasters.

IV. Since haphazard development impedes the operations of relief organizations, especially during emergencies, it is recommended that proper spatial planning should be carried out in the major cities in the country. This should be done in collaboration with disaster relief organizations to ensure that spaces are created for emergency response.

\section{References}

[1]. Aboagye, D., Dari, T. and Koomson, J. (2013) Risk Perception and Disaster Management in the Savannah Region of Ghana, International Journal of Humanities and Social Science Vol. 3 No. 3; pg. 1.

[2]. Addai, E. K., Tulashie, S.K., Annan, J.S. and Yeboah, I. (2017). Trend of Fire Outbreaks in Ghana and Ways to Prevent These Incidents, Safety and Health at Work 7 (2016) 284-292.

[3]. Allotey, N. K., Arku, G. and Amponsah, P. E. (2010) Earthquake-disaster preparedness: The Case of Accra, International Journal of Disaster Resilience in the Built Environment, Vol. 1 No. 2, 2010, pp. 140156.

[4]. Altay, N., and Green, W. G. (2006). OR/MS research in disaster operations management. European Journal of Operational Research, 175(1), 475-493 is:

[5]. Barbarosog lu, G., O “ zdamar, L. and C, evik, A. (2002), An interactive approach for hierarchical analysis of helicopter logistics in disaster relief operations, European Journal of Operational Research, Vol. 140, pp. 118-33.

[6]. Bempah, S. A. and Øyhus. A.O. (2017): The role of social perception in disaster risk reduction: Beliefs, perception, and attitudes regarding flood disasters in communities along the Volta River, Ghana, International Journal of Disaster Risk Reduction 23 (2017) 104-108.

[7]. Buatsi, S.N. (2007), Humanitarian logistics: context and challenges in Ghana and Africa, International Conference on humanitarian logistics in Ghana.

[8]. Christopher, M., \& Tatham, P. (2011). Introduction. In M. Christopher and P. Tatham (Eds.), Humanitarian logistics. Meeting the challenge of preparing for and responding to disasters (pp. 1-14). London: Kogan Page.

[9]. Disaster Management Center (1991), Disaster Management Lifecycle, University of Wisconsin Kovacs, G. and Spens, K., M. (2007) Humanitarian logistics in disaster relief operations, International Journal of Physical Distribution \& Logistics Management, Vol. 37, Issue 2, pp. 99-114.

[10]. Lamont, J. (2005), “KM's role in the aftermath of disaster”, KM World, Vol. 14 No. 10, pp. 1-2.

[11]. Long, D and Wood D (1995) The logistics of famine relief, The Journal of Business Logistics, Vol. 16, Issue 1, pp. 213-229.

[12]. Ludema, M.W. (2000), "Military and civil logistic support of humanitarian relief operations", in Arnold, E. and Walden, D. (Eds), A Decade of Progress - A New Century of Opportunity, Proceedings of the 10th Annual International

[13]. Symposium of the International Council on Systems Engineering, INCOSA, Minneapolis, MN, pp. 143150.

[14]. NADMO (2014) Nadmo News, the Official Newsletter of the National Disaster Management Organization (NADMO)". No. 4 Vol. 3.

[15]. Nisha de Silva, F. (2001), "Providing special decision support for evacuation planning: a challenge in integrating technologies", Disaster Prevention and Management, Vol. 10 No. 1, p. 1.

[16]. Ntajal, J., Lamptey, B, L., Mahamadou, I. B. and Nyarko, B.K. (2017). Flood disaster risk mapping in the Lower Mono River Basin in Togo, West Africa International Journal of Disaster Risk Reduction 23 (2017) 93-103.

[17]. Okoampa, E. (2007), oral sources, presentations and workshop discussions, Accra, World Vision Ghana.

[18]. Pedersen, P.O. (2003), Development of freight transport and logistics in Sub-Saharan Africa: Taaffe, 
Morrill and Gould revisited, Transport Reviews, Vol. 23 No. 3, pp. 275-97.

[19]. Pettit, S. J., and Beresford, A. K. C. (2005). Emergency relief logistics: An evaluation of military, nonmilitary, and composite response models. International Journal of Logistics: Research and Applications, 8(4), 313-331.

[20]. Safran, P. (2003), a strategic approach for disaster and emergency assistance, Paper presented at the 5th Asian Disaster Reduction Center International Meeting and the 2nd UN-ISDR.

[21]. Simpson, D.E. (2010) Fire protection and safety. A presentation of Ghana National Fire Service (GNFS). Ashanti Regional office at a Symposium of Building Technology Students Society (BTSS) Week celebration, Kwame Nkrumah University of Science and Technology (KNUST), Kumasi, 24-27 March 2010. SLEP]

[22]. Tomasini, R. and Van Wassenhove, L. N. (2009a). From preparedness, to partnerships: Case study research on humanitarian logistics, International Transactions in Operational Research, 16(5), 549-559.

[23]. Tomasini, R. and Van Wassenhove, L. N. (2009b), Humanitarian Logistics. London: Palgrave Macmillan.SEEP van Wassenhove, L.N. (2006), Humanitarian aid logistics: supply chain management in high gear, Journal of the Operational Research Society, Vol. 57 No. 5, pp. 475-89.

[24]. Yin, R. K. (2004). Case Study Research: Design and Methods, $3^{\text {rd }}$ Ed. Sage, Thousand Oaks, CA. 